\title{
The Impact of Social Media on Human Resource Management Scope Activities in Al-Futtaim and Al-Etihad Group UAE
}

\author{
Asaad Ali Karam ${ }^{1}$, Abdelkarim Fuad Kitana ${ }^{2}$ \\ ${ }^{1}$ Recreation \& Ecotourism Department, University of Duhok, Iraq \\ ${ }^{2}$ HRM Department, City University College in Ajman, United Arab Emirates \\ Correspondence: Abdelkarim Fuad Kitana, HRM Department, City University College in Ajman, Ajman, Sheikh \\ Ammar Road, Al Tallah 2-Ajman, United Arab Emirates.
}

Received: November 22, 2018

Accepted: December 3, 2018

Online Published: December 6, 2018

doi:10.5539/ibr.v11n12p145

URL: https://doi.org/10.5539/ibr.v11n12p145

\begin{abstract}
Purpose: Social media (SM) has gotten developing consideration over the most recent couple of years due to public awareness, a new age of organization, knowledge, and technology reasons, the requirement of SM has increased. The present research concentrates on two companies; namely Al-Futtaim and Al-Etihad group. Design/methodology: The study has identified various contextual relationships to the identified SM. Therefore, structural models of SM for implement human resource management scope activities (HRMSA). The finding presented that the companies with a larger service network is more affected by SM than the newly established company in HRMSA. Furthermore, the study indicated a positive and high relationship. Reasonable ramifications: Obvious comprehension of these variables will assist associations to organize better and deal with their assets in a productive and powerful way. Uniqueness: Contribute to study was identifying the HRMSA to implement SM platforms in (UAE) companies; Moreover, SM has opened a new avenue for HRMSA.
\end{abstract}

Keywords: employee behavior, HRM, scope activities, smartPLS3, social media

\section{Introduction}

The world has witnessed another slightly communicating system in the previous decade, which in the least amount of time not only has registered its importance of today's world of communication but also become a radical platform for expression in perspective. We were evident the impact on social media in all aspect of our life whether its politics, entertainment, business, education, etc. Societal issues, ethical dilemmas, and environmental concerns are addressed with the help of social networking sites (Korff et al., 2017). Indicating to business perspective, in traditional approach, SM has spurred despite a new medium of advertisement for products but in the contemporary world, it has registered its presence in all aspects of business whether finance, marketing, logistic or HR with the help of social media, companies can improve their relationship with target customers irrespective of geographical boundaries. These days, organizations are utilizing several social networking sites; Twitter, Facebook, LinkedIn, Pinterest, and Instagram, etc. an increasing brand visibility (Freer, 2011).

Human resources management scope activities have else understood the prominence of SM with current, while the future business world and made serious steps to include social media in its functioning. Today, whether it's about hiring employees or making a communication group of professionals to receiving feedback on the company's policy the social media is used as a first-hand platform (Madia, 2011). The HR department is equally responsible for formulating the social media policy on employees (Kaur, and Zafar, 2014). This is done to monitor them with regard to the usage of social media (whether it is for personal reason or excellent reason.) and its impact on the company's reputation (Rudnick and Wyatt, 2007). The researchers went to two of the companies, namely, Al-Futtaim and Al-Etihad to conduct a survey on the influence of SM over HRMSA. The investigator had conducted an interview concerning HR professionals of both companies and documented the response from the coming paragraph. However, the conclusion in the light of all information collected by researchers from the companies' HR professionals through the interview and the survey conducted the effect of SM respecting HRMSA.

In addition, the problem of study; SM has expanded over last, with company decade, bestowing various 
platforms to share task space to cooperate with customers and users and produce main output announcements. SM effectiveness during an HR industry is universally accepted in the corporate world. First, nag and badgering: a few representatives may utilize their online networking account to show their perspectives of work and with their manager or kindred representatives. Second, harm to boss' open notoriety; the representatives got disappointed or upset with a circumstance which has happened up to work, also employees may share on their social media platforms to appear their perspectives about the circumstance. Third, the staff posting negative comments about company business and business clients. Fourth, can the company use information about candidates posted on social media platforms to promote the company when they make recruitment decisions?

\subsection{Objectives of the Study}

The study will endeavor to reach its aim through the following research questions:

1- How social media contributes positively to HRMSA in The United Arab Emirates companies?

2- Does there is any relationship between social media and employee activities?

3- Does there is any relationship between social media impact on HR and size of the company?

4- Does there is any relationship between social media, users, and scope of HRM (employees hiring, remuneration, employee satisfaction, employee maintenance, industrial relations, and prospects of employees)?

\section{Literature Review and Hypotheses Development}

The topic of the effect of SM over HR has discussed beside various authors. The impact of social media on any issue has been shown its effect of the social crisis in the US (Oh, O. Agrawal and Rao, H., 2013). The SM equally has effectiveness within the performance of the company. Today social media is not limited to the marketing and sales it has its impact on all aspect of the business (Anderson, 2012). The effect of an SM within business is not a new issue history also has witnessed many events when media causes an effect on the business (Edosomwan et al., 2011).

Subsequently, web-based social networking is characterized to be systems which interface huge numbers of clients worldwide for oneself advantages, perspectives, and diversions (Karam, A. A., and Saydam, S. 2015). Web journals, YouTube, MySpace, Facebook are cases of SM that is regular for a scale of clients. (Sin and Al-Agaga, 2012). As per to study, the unique prospect of an SM and a gigantic regularity has inspired business pursuit like promotion along with advertising (Hanna et al., 2011).

The social media platforms represent a developing advancement with the likelihood to think about the versatility, revamping, and utmost flexibility handiness asked for by response association for their information frameworks (Sutton and Shklovski, 2008). The strength of SM web-based social networking promotions to be able to not just ease far-reaching communication and reinforce data streams, yet additionally be adaptable into the necessities of the respondents. Online networking innovations have been beforehand utilized as part of calamity reaction, yet almost no investigation has been directed considering their effect on HRM, and specific information sharing and use amongst the respondent organization. These innovations demonstrate users the capacity to react rapidly to changes in the information about ambiance and give modification, flexibility, ease of use, and adaptability in both the framework and the data. The SM back up the creation from occasional user's technique promising the surge of idea and learning by allowing the proficient time, prevalence, involvement along with modifying/purify from enlightening matter (Constantinides and Fountain, 2008). The expectation of an employee with the services of the HR depends on various variables, namely, diversion, interaction, and function that lead to the satisfaction with the employees with employment (Fodness and Murray, 2007).

The author Tsai and Chou, (2011) introduced a model to evaluate the differences between the expectations of the services provided by the airport to the customer to the effective services in order to adopt the model to discover ways to reduce the differences. The presence of control and responsibility varieties of associations is within reach and a grand idea to be related to certain organizational conditions (Kitana, A., and Karam, A. A. 2017). Most human resource strategy scientists have adopted a behavioral viewpoint (Arthur, 1994). However, the association strategic, inventive HRA are apparently going to pass on a dispatch about authoritative help into workers. This pursuit moves beyond the conventional HRA that select, hold and control operator via administering to and demonstrating a sense of duty regarding representatives (Whitener, 1997). Rendering to Mahmood A., (2012) argue that training influence on regulation, involvement and retention towards operator performance. The data was gathered from 100 workers of the administration area at Rawalpindi Islamabad Regression strategy has been utilized as part of this examination. 
The regression analysis affirmed that fulfillment and mode for qualified success have an immediate and valuable impact on organizational responsibility and expands the work effectiveness of representatives. A study utilizing this viewpoint lies on the regularly certain presumption that the effective execution of a business technique requires an interesting arrangement of worker practices and mentalities and attitudes of human resource policies and practices will inspire those practices and states of mind (Cappelli and Singh, 1992). As per Armstrong, M. (2006) before hiring a new employee, the entrepreneur ought to measure a few meditations. The initial step the entrepreneur should take while contemplating an extension of representative finance is to genuinely survey the status of the association itself.

Hypothesis:

$\mathrm{H}_{1}$ : There is a considerable effect on SM accessibility and HRM scope activities.

$\mathrm{H}_{2}$ : There is a considerable effect on SM behavior and HRM scope activities.

$\mathrm{H}_{3}$ : There is a considerable effect on SM building relationships and HRM scope activities.

$\mathrm{H}_{4}$ : There is a considerable effect on SM confidence and HRM scope activities.

$\mathrm{H}_{5}$ : There is a considerable effect on SM credibility and HRM scope activities.

$\mathrm{H}_{6}$ : There is a considerable effect on SM relevance and HRM scope activities.

$\mathrm{H}_{7}$ : There is a considerable effect on SM monitoring and HRM scope activities.

\section{Research Methodology}

Research Design: The consideration takes over a quantitative and qualitative survey from the elementary implement applied into aggregate a data through survey. The factual strategy utilized as a part of this examination, gathering numerical information about break-down using measurable strategies. While the poll utilized as a part of the present research as a self-designed survey, along with, the analyst alluded to a few examinations, that is comparable for this domain. The questionnaire designed in the English language. Therefore, population and sampling methods of investigation into both approaches; the researcher used a survey to conduct this study. The analysts demonstrated that there are a massive range of sorts of samples; Kothari, C., (2004) demonstrated that fundamentally 2 type of samples, random samples/non-random. On the other hand, the non-random sample is the techniques to collect the data which represent 100 employees distribute over two companies (Al-Futtaim group, and Al Etihad Airways) in the present study.

\subsection{Data Collection}

The researcher has conducted interview for the HR employees in two companies. The researcher also has carried out a survey to collect a response to employees working there. The specialist encrypted the information gathered over the survey including two sections of question Independent Variable Social Media; Credibility, Relevance, Confidence, Social Media Monitoring, Building relationships, Behavior, and Accessibility, Dependent Variable HRM Scope; Employees hiring, Remuneration, Employee satisfaction, Employee maintenance, Industrial relations, and Prospects of employees played out the required information control and the measurable exploration by Smart-PLS3.

\subsection{Study Restriction}

As any questionnaire-based examination, present investigation has several restrictions. These impediments fill in as markers for a future investigation contemplate on a similar theme. Some of these constraints identify with idea about a survey as well as identified with an information accumulation method. The specialist was unable to check the precision of gathered information where it expected that answerer was giving exact information. Hence, data collected in the present research by researcher potential, thus the analyst was relied on the participation in responders.

\section{Data Analysis and Findings}

Interview Regarding Social Media

Interview of HRM professionals at Al Futtaim group:

AL - Futtaim is a conglomerate group operating since 1930.With a long legacy of the company's expansion, it has also understood the importance of social media. The company has appointed social media community manager at a different level to represent the company on this platform. The excerpt of Interview conducted by me with HR professionals of $\mathrm{Al}$ - Futtaim group is as follows - 
- Do you rely on social networking sites like LinkedIn for searching suitable candidates at the required educational qualification and experience?

Our company has a LinkedIn page as https://www.linkedin.com/company/al-futtaim. We have a community network for all employees working or worked with our company. We use LinkedIn frequently for hiring employees with the desired qualification and experience.

Do you exploit social media to stay connected with former employees?

We remain connected to our former employees also through a various forum and community. Our connection with former employees is based making our network rich and more geographically diverse.

- Do you create an online knowledge base for employees that include industrial updates and important events?

Yes, the company has created an online knowledge database and as per feedback, it has been proved helpful for both us and employees.

- Do the employees have a social platform where they can share their stories and experiences?

The company has various community pages of their own namely on a Linkedin, face book and twitter where they can share their experience with the company. Apart from that employees use the various independent communities as a gal's door, etc to give feedback and share their stories.

- Do you monitor the time spent by employees on social networking sites during office hours as it can hamper their productivity?

Yes, we take a monthly report from the IT department to review the working pattern of employees and the time spends by them on social media.

- Does the company have a social media policy?

We have appointed social media community manager to publish the company's content, but we have yet not come up with any social media policy.

Interview of HRM professionals at Al Etihad Airways:

Al- Etihad Airways has started its operations from the year 2003 in Airlines Industries. The company is the second largest carriage of UAE and has shown a promising growth in last few years. In comparison to Al Futtaim, it's a new company with a disruptive model of business. The excerpts of an interview with its HR professional in a context on social media is as follows -

- Do you rely on social networking sites like LinkedIn for searching suitable candidates at the required educational qualification and experience?

The company does not strongly rely on social media sites for recruitment of its candidate, but we sometimes use it for higher authority jobs.

- Do you exploit social media to stay connected with former employees?

We do not exploit social media, but with different informal communities remain in touch with former employees.

- Do you create an online knowledge base for employees that include industrial updates and important events?

No, we have not created any such knowledge portal yet.

- Do the employees have a social platform where they can share their stories and experiences?

We have our social media pages where employees can share their stories.

- Do you monitor the time spent by employees on social networking sites during office hours as it can hamper their productivity?

Yes, we review reports of our IT department at frequent intervals.

- Does the organization have SM arrangement?

No, the association has not come up with any social media policy yet.

\subsection{Survey Descriptive Analysis}

The consideration is directed by employees from both companies within the context of the effect of SM they feel on Human Resource Management Scope Activities (HRMSA). The result has been conducted among the various age and income group of both the companies. The result of the survey has been summaries of coming paragraphs. The Quantitative Descriptive Analysis (QDA) was improved by the Tragon Corporation in the 
mid-1970s to address the issues of quantifying sensory variety. As methods of measuring variety discernment, an unstructured line scale is utilized that methodologies continuous scales, an imperative property that allows the utilization of standard statistical procedures (Stone et al., 2008). As the Age in (Table 1) shown in the below, the sample based on demographic variables of participants, and relying on the age division, the result shows a high plurality of responders were among (28-34) years old, with (32.0\%) and the next highest age category was between (35-41) years old, with (26.0\%).

Table 1. Age

\begin{tabular}{ccccc}
\hline & Fre. & $\%$ & V. \% & Cum. \% \\
\hline $21-27$ & 23 & 23.0 & 23.0 & 23.0 \\
$28-34$ & 32 & 32.0 & 32.0 & 55.0 \\
$35-41$ & 26 & 26.0 & 26.0 & 81.0 \\
$42-48$ & 13 & 13.0 & 13.0 & 94.0 \\
$48-54$ & 6 & 6.0 & 6.0 & 100.0 \\
Total & 100 & 100.0 & 100.0 & \\
\hline
\end{tabular}

While, in the item of monthly income (Table 2) in below, the highest was (43\%) of responders were a (AED $500-800)$ with (43.0\%), following by (41\%) with a (AED 800-above).

Table 2. Monthly Income

\begin{tabular}{lcccc}
\hline & Fre & $\%$ & V. \% & Cum. \% \\
\hline AED 300-500 & 16 & 16.0 & 16.0 & 16.0 \\
AED 500-800 & 43 & 43.0 & 43.0 & 59.0 \\
AED 800 and above & 41 & 41.0 & 41.0 & 100.0 \\
Total & 100 & 100.0 & 100.0 & \\
\hline
\end{tabular}

Besides, the (Table 3) of social media assisted you to get the desired job you wanted? While, and based on the question categories, the result indicated that the high majority of responders were (Agree on a scale), with $(58.0 \%)$ and the next highest scale category was (Strongly Agree scale), with (38.0\%) the study found that the responders were completely satisfied of social media platforms.

Table 3. Social media helped you to get the desired job you wanted?

\begin{tabular}{lcccc}
\hline & Fre. & $\%$ & V. \% & Cum. \% \\
\hline D & 1 & 1.0 & 1.0 & 1.0 \\
N & 3 & 3.0 & 3.0 & 62.0 \\
A & 58 & 58.0 & 58.0 & 100.0 \\
S. A & 38 & 38.0 & 38.0 & \\
Total & 100 & 100.0 & 100.0 & \\
\hline
\end{tabular}

In regard to question a community on social media helps in grievance addresses (Table 4) which is showing below, Pay hike or HRMS related issues? The table has indicated a majority to heartily agree on a scale of (28.0\%) when the respondent has been asked the role of social media in solving HRMSA grievances or Pay hikes most of the respondent has strongly agreed that it is faster medium to communicate with management. Though some of the respondents disagreed with the role and argues the conventional approaches are still at work.

Table 4. Community on social media help in grievance addresses, Pay hike or HR related issues?

\begin{tabular}{lcccc}
\hline & Fre. & $\%$ & V. \% & Cum. \% \\
\hline S.D & 18 & 18.0 & 18.0 & 18.0 \\
D & 20 & 20.0 & 20.0 & 38.0 \\
N & 9 & 9.0 & 9.0 & 77.0 \\
A & 25 & 25.0 & 25.0 & 100.0 \\
S.A & 28 & 28.0 & 28.0 & 100.0 \\
Total & 100 & 100.0 & 100 & \\
\hline
\end{tabular}

However, the (Table 5) of a question: which of the social media sites have helped you professionally the most? The most responder was answered (Facebook 42.0\%, LinkedIn 23.0\%, Instagram 15.0\%, Twitter 13.0\%, and YouTube $7.0 \%$ ) respectively, the respondent when asked about the site that helped them most in their professional terms. They had shown a faith in Facebook most apart from that the respondent has a strong faith in their community groups. 
Table 5. Which of SMP has helped you professionally the most

\begin{tabular}{lcccc}
\hline & Fre. & $\%$ & V. \% & Cum. \% \\
\hline Twitter & 13 & 13.0 & 13.0 & 13.0 \\
Instagram & 15 & 15.0 & 15.0 & 28.0 \\
YouTube & 7 & 7.0 & 7.0 & 35.0 \\
Facebook & 42 & 42.0 & 42.0 & 77.0 \\
LinkedIn & 23 & 23.0 & 23.0 & 100.0 \\
Total & 100 & 100.0 & 100.0 & \\
\hline
\end{tabular}

Finally, on the (Table 6) indicate of question does company need to have a social media policy? The study found that the most respondent go to (Agree scale) with $44.0 \%$, when asked to the respondent about the need of social media policy 44 out of 100 respondents has shown an affirmation (Agree), and out of 100 (9 Strongly Agree), (21 Neutral) on that while the (2 Strongly Disagree), and (24 Disagree) of the respondent denied the fact on the ground that it is of no help. In concluding from descriptive analysis the reasonable ground to believe that study is dealing with actual respondents that have been visiting the company social media platforms.

Table 6. Do company need to have a social media policy

\begin{tabular}{lcccc}
\hline & Fre. & $\%$ & V. \% & Cum. \% \\
\hline S.D & 2 & 2.0 & 2.0 & 2.0 \\
D & 24 & 24.0 & 24.0 & 47.0 \\
N & 21 & 21.0 & 21.0 & 91.0 \\
A & 44 & 44.0 & 44.0 & 100.0 \\
S.A & 9 & 9.0 & 9.0 & 100.0 \\
Total & 100 & 100.0 & & \\
\hline
\end{tabular}

\subsection{R Square Analysis}

From the (Table 7) quality criteria for latent variable, which is indicated on an appendix, it has been demonstrated an intensity of the connection between autonomous factors; X1 Credibility, X2 Relevance, X3 Confidence, X4 Social Media Monitoring, X5 Building relationships, X6 Behavior, and X7 Accessibility and the $\mathrm{Y}=$ Human Resource Management Scope Activities reflected by R-value as subordinate variable. The $\left(\mathrm{R}^{2}\right)$ has demonstrated the regression show execution. The most grounded esteem was the efficiency of the entire paradigm. During, the $\left(\mathrm{R}^{2}\right)$ esteem has demonstrated autonomous factors were emphatically affecting on the HRMSA a subordinate factor. Along these lines, it has been demonstrated that the $\left(\mathrm{R}^{2}\right)$ was showed up (.77118) along with $(75.358 \%)$ a variation in DV and this could be illustrated through IV variation, with significant P-value (0.000).

Table 7. Quality criteria for latent variable

\begin{tabular}{lccccc}
\hline & $(\mathrm{O} . \mathrm{S})$ & $(\mathrm{S} . \mathrm{M})$ & $(\mathrm{STDEV})$ & $\mathrm{S} . \mathrm{T}(|\mathrm{O} / \mathrm{STDEV}|)$ & $(\mathrm{P} . \mathrm{V})$ \\
\hline HRMSA & 0.7711 & 0.7921 & 0.0405 & 19.0375 & 0.0000 \\
R Square Adjusted & 0.7535 & 0.7761 & 0.0436 & 17.2742 & 0.0000 \\
\hline
\end{tabular}

HRMSA; Human Resource Management Scope Activities

\subsection{PLS Path Model Estimation}

Based on the conceptual model on the (Figure 1), the social media, is dragged to utilize the "repeated indicators approach" factors of slash level, respectively (e.g., Credibility, Relevance, Confidence, Social Media Monitoring, Building relationships, Behavior, and Accessibility) they prevail again for the identical bigger level factor (e.g., Human Resource Management Scope Activities). The PLS-SEM algorithm is controlled by utilizing "Calculate by PLS Algorithm" and effectively assembles with the instruction proposed through (Hair et al., 2013). As per to study, specialists can appropriately evaluate the "path coefficients" in the basic model; the analyst should first look at the pointer dependability, inward consistency reliability, discriminant legitimacy, and the concurrent validity of the reflective estimation paradigm to guarantee they are attractive (Wong, K., 2013). 


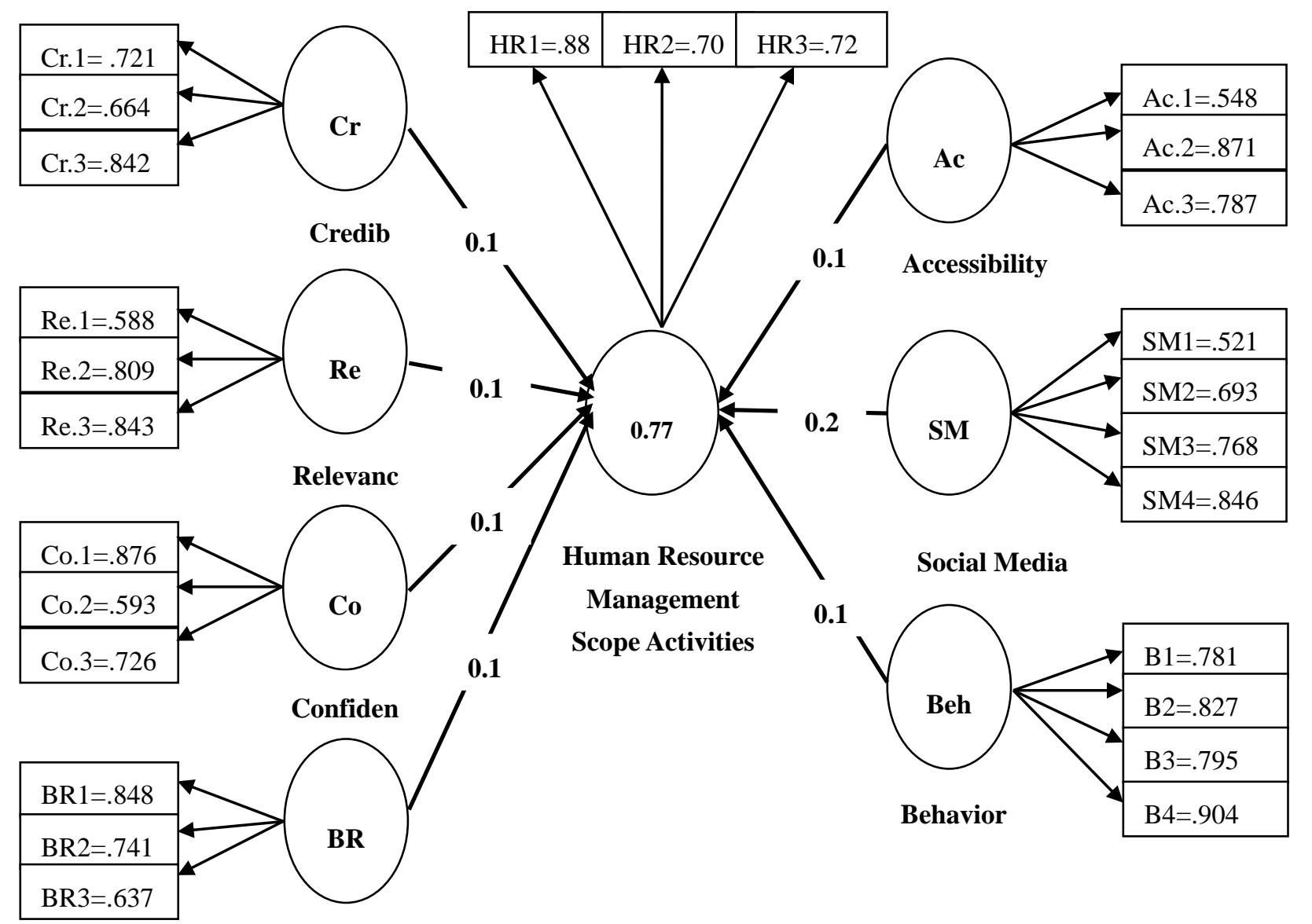

Building Relationships

Figure 1. Conceptual Model

Source: Based on AA Karam \& A Kitana (2018).

\subsection{Reliability of Inward Consistency}

Based on the mentioned program, composite dependability, as opposed to "Cronbach's alpha", is utilized for consider an estimation paradigm inward consistency reliability. An inward consistency is customarily limited utilizing Cronbach's alpha. Nevertheless, it is non-reasonable for PLS-SEM in light of the fact that it is touchy to a quantity of items in the criterion, and this is likewise established to create extreme underrating while connected to the program paradigm (Henson, 2001). In present study, the composite reliability to the constructs Accessibility, Behavior, Building Relationships, Confidence, Credibility, Relevance, Social Media Monitoring and Human Resource Management Scope Activities are indicated to be 0.78654 0.89671, 0.78897, 0.78094, $0.78880,0.79568,0.80466$, and 0.79348 severally, point out raise altitudes of inward consistency reliability (Osburn, 2000). Earlier investigation proposes that a doorstep altitude of 0.60 or soaring is desired to demonstrate a tasteful composite reliability in investigational study Pereira and Pinto, (1992) but not overrun the (0.95) level. Therefore, so as the rate of the statistic is one yet, it acts not mean completeness in composite reliability due to is a solitary thing feature.

\subsection{Validity of Convergent}

Convergent validness indicates to a paradigm capability to clarifying the indicator's variation. The average variation extracted ability supply proof of convergent validness (Russell, 1978). Research suggests an average variety extracted doorstep scale of (0.5) as confirmation of convergent validness. However, two of study develops exceeded this grade and the rest are not very far from this scale (Bagozzi, and Yi, 1988). After these build met discriminant legitimacy and latest reliability investigations; they are protected against the paradigm to preserve purport validity. The average variation extracted from the latent variable as shown in (Table 8) summary, of, construct reliability, validity bigger than (0.05), therefore, the $(0.5)$ is the lower standard desired. In this way, the standard of reflective build's proving to gain the abnormal altitude of convergent validity. 


\subsection{Construct Reliability, and Collinearity Statistics (VIF)}

Based on reliability which is a status to validity, loadings accuracy is the essential chequered to include the relevance to measure have much on popular to capture via dormant variables. Subsequent to analyzing the external loadings from each LVs (credibility, relevance, confidence, social media monitoring, building relationships, behavior, and accessibility, and the human resource management scope activities, indicators that are shown exterior loadings bigger from (.4) doorstep altitude (Hair et al., 2013). Therefore, all indicators are establishing to have factors between (.5) to (.9). A factor pertinence experiment is consequently carrying out into these each factor to inform whether they ought to be held in the paradigm. Hence, this could be enough evidence that all indicators indicate extremely dynamic relationships. In an indicator's importance, experiment, dubious factors ought to be erased just if their expulsion from the PLS paradigm prompts an expansion of an AVE and composite reliability (CR) of their builds over the (.5) limits these can be gotten from (Table 8) through review criteria diagram. As the disposal of these, all factor would bring about an expansion of (AVE) and (CR) of their particular dormant variables. The indicators are retained because there (OL, LR, rho_A, CR, and AVE) are all $(>0.5)$ or higher which all are statically significant. The LVs ought to retain the capacity to clarify no less than (half) of every factor's variance. By PLS calculation, the subsequent path-coefficient's paradigm assessment is displayed in (Figure 1) and the OLs of various builds are shown on (Table 8).

Table 8. Summary of Construct Reliability, Validity

\begin{tabular}{|c|c|c|c|c|c|c|c|}
\hline & Indicators & $\begin{array}{c}\text { Outer } \\
\text { Loadings }\end{array}$ & $\begin{array}{l}\text { Loadings } \\
\text { Reliability }\end{array}$ & rho_A & $\begin{array}{l}\text { Composite } \\
\text { Reliability }\end{array}$ & AVE & $\begin{array}{c}\text { Collinearity } \\
\text { Statistics (VIF) } \\
\text { SM } \\
\end{array}$ \\
\hline & $\mathrm{AC} 1$ & 0.54843 & \multirow{4}{*}{0.58868} & \multirow{4}{*}{0.64674} & \multirow{4}{*}{0.78654} & \multirow{4}{*}{0.55959} & \multirow{3}{*}{1.85709} \\
\hline \multirow[t]{3}{*}{ Accessibility } & $\mathrm{AC} 2$ & 0.87095 & & & & & \\
\hline & AC3 & 0.78704 & & & & & \\
\hline & BE1 & 0.78058 & & & & & \\
\hline \multirow{4}{*}{ Behavior } & BE2 & 0.82680 & \multirow{4}{*}{0.84612} & \multirow{4}{*}{0.85320} & \multirow{4}{*}{0.89671} & \multirow{4}{*}{0.68530} & \multirow{4}{*}{2.13741} \\
\hline & BE3 & 0.79474 & & & & & \\
\hline & BE4 & 0.90371 & & & & & \\
\hline & BR1 & 0.84823 & & & & & \\
\hline \multirow{3}{*}{ Building Relationships } & $\mathrm{BR} 2$ & 0.74066 & \multirow[t]{3}{*}{0.62383} & \multirow[t]{3}{*}{0.66837} & \multirow[t]{3}{*}{0.78897} & \multirow[t]{3}{*}{0.55810} & \multirow[t]{3}{*}{2.55896} \\
\hline & BR3 & 0.63738 & & & & & \\
\hline & $\mathrm{Col}$ & 0.87649 & & & & & \\
\hline \multirow[t]{3}{*}{ Confidence } & $\mathrm{Co} 2$ & 0.59300 & \multirow[t]{3}{*}{0.60967} & \multirow[t]{3}{*}{0.72016} & \multirow[t]{3}{*}{0.78094} & \multirow[t]{3}{*}{0.54916} & \multirow[t]{3}{*}{2.34678} \\
\hline & $\mathrm{Co} 3$ & 0.72635 & & & & & \\
\hline & $\mathrm{Crl}$ & 0.72137 & & & & & \\
\hline \multirow[t]{3}{*}{ Credibility } & $\mathrm{Cr} 2$ & 0.66406 & \multirow[t]{3}{*}{0.60130} & \multirow[t]{3}{*}{0.63057} & \multirow[t]{3}{*}{0.78880} & \multirow[t]{3}{*}{0.55702} & \multirow[t]{3}{*}{2.96881} \\
\hline & $\mathrm{Cr} 3$ & 0.84244 & & & & & \\
\hline & Rel & 0.58798 & & & & & \\
\hline \multirow[t]{3}{*}{ Relevance } & $\operatorname{Re} 2$ & 0.80935 & \multirow[t]{3}{*}{0.63705} & 0.70994 & 0.79568 & 0.57042 & 3.03829 \\
\hline & Re3 & 0.84290 & & & & & \\
\hline & HRMSI & 0.82248 & & & & & \\
\hline HRMS & HRMS2 & 0.69956 & 0.61490 & 0.63792 & 0.79348 & 0.56279 & DV \\
\hline & HRMS3 & 0.72285 & & & & & \\
\hline & SMM1 & 0.52132 & & & & & \\
\hline & SMM2 & 0.69318 & & & & & \\
\hline Social Media Monitoring & SMM3 & 0.76802 & $0.6 / 975$ & 0.73357 & 0.80466 & 0.51445 & 2.59909 \\
\hline & SMM4 & 0.84599 & & & & & \\
\hline
\end{tabular}

Moreover, the measure of collinearity statistics "variance inflation factor" (VIF) human resource management scope activities dependent variable; therefore VIF compute the effect of collinearity into the ingredients during an inner VIF values in smart-PLS. The VIF is constantly more noteworthy than or equivalent of one, tolerance, it's up to one. There is eternally approved VIF esteem until deciding nearness from multi-collinearity. Estimating about VIF with a view to surpass ten are frequently viewed as multi-collinearity, however, during feeble paradigms admires over two and halves might be a reason into worry. In countless insights, programs, the outcomes are demonstrated both as an individual $\mathrm{R}^{2}$ esteem (unmistakable from the general $\mathrm{R}^{2}$ of the model) and a Variance Inflation Factor (VIF). At the point when those $\mathrm{R}^{2} / \mathrm{VIF}$ esteems are bigger from each factor of the paradigm, multi-collinearity are likely a matter at the point when VIF is bigger, there is high multicollinearity and unpredictability of the $\mathrm{b}$ and beta coefficients. It is regularly compact to deal with this. For more, evidence of all LVs inner VIF values was (between1-3) as indicated on (Table 8) which is far enough to show statistically significant (Ringle et al., 2015). 


\subsection{Discriminant Validity}

As per Fornell-Larcker Criterion (Table 9) results and specification as the same researcher in (1981) is a familiar while traditionalist method of evaluate "discriminant validity" in Smart-PLS-SEM. An additional way is a cross stacking analysis, the factors stacking to its latent variables ought to be inflated than other constructs. Hence, the square root of each latent factor ought to be bigger of latent factors connection to establish the discriminant validity. As indicated in (Table 8) plainly the discriminant validity will stretch to present study due to the square root of AVE for Credibility, Relevance, Confidence, Social Media Monitoring, Building relationships, Behavior, and Accessibility are much larger than the corresponding LFC. Hence, the numbers are bigger through correlation rates within column about (Accessibility.74806), (Behavior. 82783) (Building Relationships.74706), (Confidence.74105), (Credibility.74634), (Relevance.75526), (HRMS.76772), and (Social Media Monitoring.71725), and likewise higher than those in the (row). An abridged, to each factor, the estimations of square roots are greater than an AVE extricated estimations. Generally, the discriminant validity was well established.

Table 9. Fornell-Larcker Criterion

\begin{tabular}{|c|c|c|c|c|c|c|c|c|}
\hline & $\mathrm{AC}$ & $\mathrm{BE}$ & $\mathrm{BR}$ & Co & $\mathrm{Cr}$ & $\operatorname{Re}$ & HRMS & SMM \\
\hline Accessibility & 0.748 & & & & & & & \\
\hline Behavior & 0.066 & 0.827 & & & & & & \\
\hline Building Re. & 0.395 & 0.565 & 0.747 & & & & & \\
\hline Confidence & 0.423 & 0.419 & 0.656 & 0.741 & & & & \\
\hline Credibility & 0.517 & 0.540 & 0.648 & 0.637 & 0.746 & & & \\
\hline Relevance & 0.447 & 0.582 & 0.561 & 0.643 & 0.727 & 0.755 & & \\
\hline HRMS & 0.534 & 0.596 & 0.721 & 0.689 & 0.722 & 0.738 & 0.767 & \\
\hline SM. Mo. & 0.530 & 0.482 & 0.641 & 0.628 & 0.591 & 0.673 & 0.750 & 0.717 \\
\hline
\end{tabular}

4.8 Path Coefficients

From the (Table 10) in appendix, path coefficients have specified the intensity of connection with the model latent factors with constant of determination $\left(\mathrm{R}^{2}\right)$ was indicated the effect on all LVs to investigate the hypothesis significantly. The significance decision level by researchers refuse (H0) is self-assertive. Routinely the five percentages (fewer from one out of twenty shot being off-base), $0.1 \%(\mathrm{P}<0.05,0.01$ and 0.001 ) ranks to have been utilized. This numeral can grant an incorrect discern from a safeguard. Hence, Accessibility H1, Behavior H2, Building relationships H3, Relevance H6, and Social Media Monitoring H7, were showing statistically significant with P-value smaller than (0.05). Whilst the hypothesis of Confidence H4 and Credibility H5 were rejected because of the P-value was higher of (.05).

Table 10. Path Coefficients

\begin{tabular}{lcccccc}
\hline & $(\mathrm{O} . \mathrm{S})$ & $(\mathrm{S} . \mathrm{M})$ & $(\mathrm{STERR})$ & T.S $(|\mathrm{O} / \mathrm{STERR}|)$ & $(\mathrm{P} . V)$ & Hypothesis \\
\hline Accessibility ->HRMSA & 0.145 & 0.149 & 0.063 & 2.289 & 0.022 & Accepted \\
Behavior -> HRMSA & 0.170 & 0.172 & 0.065 & 2.589 & 0.009 & Accepted \\
Building R-> HRMSA & 0.170 & 0.161 & 0.063 & 2.683 & 0.007 & Accepted \\
Confidence -> HRMSA & 0.115 & 0.130 & 0.085 & 1.345 & 0.179 & Rejected \\
Credibility -> HMRSA & 0.105 & 0.101 & 0.074 & 1.417 & 0.157 & Rejected \\
Relevance -> HRMSA & 0.150 & 0.15 & 0.078 & 1.932 & 0.050 & Accepted \\
SMM-> HRMSA & 0.262 & 0.258 & 0.085 & 3.075 & 0.002 & Accepted \\
\hline
\end{tabular}

In concluding, during hypothesis testing by path coefficients in smart-PLS, each parameter assessments for identical hypotheses examined. Furthermore, a comprehensive effectiveness to conjecture that is achieved. Thus, a test statistically significant at the different levels, confirmed five from hypotheses, through their criterion valuation. Moreover, a statistical measure which is the $\left(\mathrm{R}^{2}\right)$ for clarifying the variance in IV and DV upon paradigm that demonstrated on (Table 7). However, all estimations of $\left(R^{2}\right)$ having demonstrated the intensity of the association with ( $\mathrm{P}$-value $=.00$ ), from seven inactive factors on a paradigm were interpreted significant levels $(1 \%-5 \%)$. As SPLS3 was specified $\left(\mathrm{R}^{2}\right)$ into comprehensive framework of a paradigm, this could be a better grade in combination paradigm rather to that if an SPLS discovers several troubles it might not confirm $\left(\mathrm{R}^{2}\right)$ to all paradigm.

\section{Discussion and Conclusion}

While concluding, a role of SM on HRMS is not deniable now, but it is still in its nascent stage. Based on the interview done by a researcher and the survey conducted to the conclusion that the companies which are established several decades ago (like Al-Futtaim) has assembled the effect of social media in a better way than the companies with the less establishment period. Secondly, the study found that as Al Futtaim is a big conglomerate with widespread business, it has a more extensive use of social media and has more concrete plans 
in comparison to Al-Etihad which mostly take help of social media when needed in HRMSA. Though from the survey and interview the study get to know that no one has still implemented any social media policy but Al Futtaim is in a mood to adapt it while Al- Etihad do not see its need in recent years. Specifying the achievement of SM within broadly and their creating application for associations specifically, the investigation theme has likewise turned out to be vital for organizational examination and HRMS. Albeit SM gives numerous open doors, e.g., for a viable undertaking and credibility administration, the study has mentioned out some potential threats. This empowered us to grant numerous exact examinations on the open doors, and dangers of SM utilize a structure that considers reflection from lone occurrences, for which implies it takes into account summing up an HRMS pertinent subject in connection for web-based social networking and, along these lines, for information exchange inside the HRMSA.

Through a testimonial to innovation and socialite construction, the study has indicated how authoritative and singular vigour may change while occurring in simulated environments concerning to HRMS. Firstly, the outline, through the specialized design of SM, limits yet in addition empowers proven activities. This can combination, and the hierarchical body while decides how ordinary activities are facilitated. In this manner, to view innovation as existence firmly identified with a sociable situation, Orlikowski and Scott, (2008), the ability viewed as an interest in resolve post-processing job. Next, the study determined another variety of association in order to counterpart the customary zones of collaborations with organizations as a component of enrollment. One of the study situations, some portion of the association's workforce was expressible inside a shut situation with its own particular principles of conduct. In connection to SM, the study beholds the uniqueness of a specific birth companion as existence applicable to HRMS. Digital locals and post-computerized locals, as the most youthful companions in associations, convene their own particular desires, in research vision, progressively diffuse in associations that will come about, we expect, in some serious variations into communication and conduct.

The HRMS activities spotted out the present study whilst the HRMS academic clarifications consider several functional ramifications during an importance technical framework, organization design, with information systems design. The activities concerning related standards could prompt improvements and usage of extra effective on technical and sociable situations as far as the open doors and threats to utilizing SM. Otherwise, the analysts would prescribe administration should play a dynamic part in the use of SM, for instance, by making a sufficient situation for group building, masterminding the specialized premise, and tuning the principles of conduct through Accessibility, Behavior, Building Relationships, Confidence, Credibility, Relevance, Social Media Monitoring, and Human Resource Management Scope Activities. Subsequently, accordingly leads should be sanctioned in ordinary practices; administrative nearness in SM conditions ought to be compulsory. The study assumes tuning the plan of correspondence pattern and points via partaking in ordinary correspondence is an essential authority task.

Eventually, based on the above survey concludes that an effect of social media has increased from recent times for HRMSA. But the involvement is still very informal and a lot needed to be done to make it a formal and reliable platform for human resource management scope activities. Regardless of the possibility that researching SM outlines has contrasted with exploring vis-a-vis confront, a few points of interest in the information (the discussion is put away as content, which offers the chance to dissect it ex-post), some sort of triangulation with different sources, for example, talk about the information and data from members perception, will even know as a basic. Therefore, in this case, would have gone past the objectives of present survey and should be left to future research.

\section{Acknowledgement}

We would like to thank the all members of two companies Al-Futtaim and Al-Etihad group UAE for their participation in the survey who supported our work in this way and helped me get results of better quality. We also grateful to the our universities for their patience and support in overcoming numerous obstacles I have been facing through our research.

\section{References}

Anderson, C. K. (2012). The impact of social media on lodging performance. Cornell Hospitality Report, 12(15), 4-11.

Armstrong, M. (2006). Human resource management practice. London: Kogan page limited.

Arthur, J. B. (1994). Effects of human resource systems on manufacturing performance and turnover. Academy of Management journal, 37(3), 670-687.

Bagozzi, R. P., \& Yi, Y. (1988). On the evaluation of structural equation models. Journal of the Academy of 
Marketing Science, 16(1), 74-94. https://doi.org/10.1007/BF02723327

Cappelli, P., \& Singh, H. (1992). Integrating strategic human resources and strategic management. Research Frontiers in Industrial Relations and Human Resources, 165, 192.

Constantinides, E., \& Fountain, S. J. (2008). Web 2.0: Conceptual foundations and marketing issues. Journal of Direct, Data and Digital Marketing Practice, 9(3), 231-244. https://doi.org/10.1057/palgrave.dddmp.4350098

Edosomwan, S., Prakasan, S. K., Kouame, D., Watson, J., \& Seymour, T. (2011). The history of social media and its impact on business. Journal of Applied Management and Entrepreneurship, 16(3), 79.

Fodness, D., \& Murray, B. (2007). Passengers' expectations of airport service quality. Journal of Services Marketing, 21(7), 492-506. https://doi.org/10.1108/08876040710824852

Fornell, C., \& Larcker, D. F. (1981). Structural equation models with unobservable variables and measurement error: Algebra and statistics. Journal of Marketing Research, 382-388. https://doi.org/10.1177/002224378101800313

Freer, T. (2011). Social media gaming-a recipe for employer brand success. Strategic HR Review, 11(1), 13-17. https://doi.org/10.1108/14754391211186269

Hair, J. F., Ringle, C. M., \& Sarstedt, M. (2013). Partial least squares structural equation modeling: Rigorous applications, better results and higher acceptance.

Hanna, R., Rohm, A., \& Crittenden, V. L. (2011). We're all connected: The power of the social media ecosystem. Business Horizons, 54(3), 265-273. https://doi.org/10.1016/j.bushor.2011.01.007

Henson, R. K. (2001). Understanding internal consistency reliability estimates: A conceptual primer on coefficient alpha. Measurement and Evaluation in Counseling and Development, 34(3), 177.

Karam, A. A., \& Saydam, S. (2015). An analysis study of improving brand awareness and its impact on consumer behavior via media in North Cyprus (A case study of fast food restaurants). International Journal of Business and Social Science, 6(1).

Kaur, T., \& Zafar, S. (2014). Impact of Social Media on HR Functions: A Review. Prabandhan: Indian Journal of Management, 7(3), 26-34. https://doi.org/10.17010/pijom/2014/v7i3/59279

Kitana, A., \& Karam, A. A. (2017). The relationship between work environment into women's career development and job satisfaction in the United Arab Emirates: A large scale sampling. International Journal of Business and Management Invention, 6, 22-28.

Korff, J., Biemann, T., \& Voelpel, S. C. (2017). Differentiating HR systems' impact: moderating effects of age on the HR system-work outcome association. Journal of Organizational Behavior, 38(3), 415-438. https://doi.org/10.1002/job.2130

Kothari, C. R. (2004). Research methodology: Methods and techniques. New Age International.

Madia, S. A. (2011). Best practices for using social media as a recruitment strategy. Strategic HR Review, 10(6), 19-24. https://doi.org/10.1108/14754391111172788

Mahmood, A. (2012). Impact of Training on Commitment, retention and performance. Islamabad: Foundation University, Islamabad.

Oh, O., Agrawal, M., \& Rao, H. R. (2013). Community intelligence and social media services: A rumor theoretic analysis of tweets during social crises. Mis Quarterly, 37(2). https://doi.org/10.25300/MISQ/2013/37.2.05

Orlikowski, W. J., \& Scott, S. V. (2008). 10 sociomateriality: challenging the separation of technology, work and organization. Academy of Management Annals, 2(1), 433-474. https://doi.org/10.5465/19416520802211644

Osburn, H. G. (2000). Coefficient alpha and related internal consistency reliability coefficients. Psychological methods, 5(3), 343. https://doi.org/10.1037/1082-989X.5.3.343

Pereira, M. V. F., \& Pinto, L. M. V. G. (1992). A new computational tool for composite reliability evaluation. IEEE transactions on power systems, 7(1), 258-264. https://doi.org/10.1109/59.141712

Ringle, C. M., Wende, S., \& Becker, J. M. (2015). SmartPLS 3. Boenningstedt: SmartPLS GmbH, http://www. smartpls. com.

Rudnick, M., \& Wyatt, W. (2007). How to integrate new technology and social media into HR processes. Strategic HR Review, 6(2), 5-5. https://doi.org/10.1108/14754390780000944 
Russell, J. A. (1978). Evidence of convergent validity on the dimensions of affect. Journal of personality and social psychology, 36(10), 1152. https://doi.org/10.1037/0022-3514.36.10.1152

Sin, S. S., Nor, K. M., \& Al-Agaga, A. M. (2012). Factors Affecting Malaysian young consumers' online purchase intention in social media websites. Procedia-Social and Behavioral Sciences, 40, 326-333. https://doi.org/10.1016/j.sbspro.2012.03.195

Stone, H., Sidel, J. L., \& Bloomquist, J. (2008). Quantitative descriptive analysis. Descriptive Sensory Analysis in Practice, 53-69.

Sutton, J. N., Palen, L., \& Shklovski, I. (2008). Backchannels on the front lines: Emergency uses of social media in the 2007 Southern California Wildfires (pp. 624-632). University of Colorado.

Tsai, W. H., Hsu, W., \& Chou, W. C. (2011). A gap analysis model for improving airport service quality. Total Quality Management \& Business Excellence, 22(10), 1025-1040. https://doi.org/10.1080/14783363.2011.611326

Whitener, E. M. (1997). The impact of human resource activities on employee trust. Human Resource Management Review, 7(4), 389-404. https://doi.org/10.1016/S1053-4822(97)90026-7

Wong, K. K. K. (2013). Partial least squares structural equation modeling (PLS-SEM) techniques using SmartPLS. Marketing Bulletin, 24(1), 1-32.

\section{Copyrights}

Copyright for this article is retained by the author(s), with first publication rights granted to the journal.

This is an open-access article distributed under the terms and conditions of the Creative Commons Attribution license (http://creativecommons.org/licenses/by/4.0/). 